\title{
Sol-Gel Materials with Pesticide Delivery Properties
}

\author{
Malina Raileanu ${ }^{1 *}$, Ligia Todan", Maria Crisan ${ }^{1}$, Ana Braileanu ${ }^{1}$, Adriana Rusu ${ }^{1}$, Corina Bradu ${ }^{2}$, \\ Adrian Carpov ${ }^{3}$, Maria Zaharescu' ${ }^{1}$ \\ ${ }^{1}$ Ilie Murgulescu Institute of Physical Chemistry, Romanian Academy, Bucharest, Romania; ${ }^{2}$ Faculty of Chemistry, Organic Chemis- \\ try Department, University of Bucharest, Bucharest, Romania; ${ }^{3}$ Petru Poni Institute of Macromolecular Chemistry, Iasi, Romania. \\ Email: mraileanu@icf.ro,malina_raileanu@yahoo.com
}

Received March 26 $6^{\text {th }}, 2010$; revised April 20 ${ }^{\text {th }}$ 2010; accepted April 25 ${ }^{\text {th }}, 2010$.

\begin{abstract}
Pesticides are widely used in agriculture, although they may create hazards both to humans and to the environment. In order to reduce the harmful effects of their administration, there has been made a great effort to find solutions. The porous sol-gel silica materials which are able to entrap different organic molecules represent new studied controlled release carriers. The aim of the present work was to prepare and characterize sol-gel composites based on trichlorfon as organophosphorous pesticide embedded in silica matrices generated from three different $\mathrm{SiO}_{2}$ sources: tetraethylorthosilicate (TEOS), colloidal silica (CS), and sodium silicate (SS). Similar samples to those containing only trichlorfon have also been synthesised, in which $\alpha$-, $\beta$-, and $\gamma$-cyclodextrin have been included in order to study the possibility of improving the release of the pesticide from the silica matrices. The porous sol-gel silica materials generated from TEOS and CS are able to entrap the trichlorfon and ensure an efficient delivery of the pesticide. In the absence of cyclodextrins, better results are obtained in the case of TEOS precursor, compared to colloidal silica. The addition of cyclodextrins in order to improve the release of the pesticide from the silica matrices was successful only in the case of $\mathrm{CS}$ as $\mathrm{SiO}_{2}$ precursor. The best release of the pesticide was obtained with $\beta-C D$.
\end{abstract}

Keywords: Sol-Gel, Tetraethylorthosilicate, Colloidal Silica, Trichlorfon, Cyclodextrin

\section{Introduction}

Nowadays, agrochemicals play an important role in making possible the continuous increase of food production. On the other hand, a high level of chemicals could become a danger for humanity. Pesticides represent one of the most important types of chemicals used in agriculture. They include a wide diversity of substances. Among them, the class of organophosphorous compounds $\left(\mathrm{OP}_{\mathrm{s}}\right)$ has gained an enormous commercial success, due to their properties of controlling moths, ants, cockroaches, termites, fruit flies and similar insects, fleas, locusts, caterpillars and ticks [1]. They are the most frequently used in many cultures, at various stages of cultivation, as common insecticides, in order to control insect and arthropod pests on vegetable crops together with the increase of crop yields [2-8]. Among the organophosphorous pesticides, trichlorfon [O,O-dimethyl-(2, 2, 2-trichloro-1-hydroxy ethyl)-phosphonate] is one of the most popular, being ex- tensively used in agriculture since 1952 as a broad spectrum insecticide [2,9-16]. One of the major problems of agriculture which must be solved refers to the controlled use of pesticides. The presence of the used pesticides in the surface and ground waters $[4,6,17,18]$ emphasises this environmental issue. As a result of the increased awareness and worry regarding the potential of pesticides to have detrimental impacts on both human and ecosystem health, there is a great interest in developing less persistent but more selective pesticides. However, their use can be too expensive because they require more frequent application. Because of the high costs and the limitations in what the design of new pesticides is concerned, the industry and the researchers have decided not to fabricate new pesticides, but to improve the delivery systems of the current ones. An effective way is using the controlled release alternative. The controlled release systems have become more and more important due to their advantages: they minimize pesticide residues available to the envi- 
ronment, thus reducing the environmental hazards and human toxicity, they increase the efficacy and the longevity of the pesticide and decrease the application costs, allowing less frequent uses [17,19-22]. Hussain [21] divides the controlled release formulations of pesticides into four main types: polymer membrane reservoirs, matrices containing physically-trapped pesticides, covalentlybounded pesticides and coated pesticide granule systems. Some examples are already mentioned in the literature [8,22-25]. As the property of the sol-gel process to prepare inorganic-organic hybrids by embedding organic molecules in the inorganic oxide matrix is a well known fact [26-35], Böttcher et al. [20] have used the sol-gel matrix as an alternative to biocide encapsulation. They prepared sol-gel composite films with controlled release properties.

The aim of the present work was to prepare and characterize sol-gel composites powders based on trichlorfon as organophosphorous pesticide embedded in silica matrices generated from three different $\mathrm{SiO}_{2}$ sources: tetraethylorthosilicate-TEOS, colloidal silica-CS, and sodium silicate-SS. Both routes of the sol-gel method (the alkoxide and the aqueous one) have been used. The aqueous route selection was based both on economical and ecological reasons: the aqueous $\mathrm{SiO}_{2}$ precursors are less expensive than TEOS and the soil attack is almost inexistent in a system in which the pesticide proceeds from an aqueous medium. Because the ability of cyclodextrins to form inclusion complexes with a wide variety of agricultural chemicals is well known [36-42], the possibility of using them in order to improve the release of the pesticide from the silica matrices has been studied. A comparison between the performances of the prepared materials has been made, in order to establish the most propitious reagents (e.g. silica precursor and type of cyclodextrin) and synthesis conditions which could lead to the best results from the point of view of the applicability.

\section{Materials and Methods}

\subsection{Preparation of Samples}

Composite samples, consisting of pesticide embedded in silica gels (pesticide/ $\mathrm{SiO}_{2}=1 / 3$ in weight), have been prepared using both routes of the sol-gel method: the alkoxide and the colloidal one. The pesticide was an organophosphorous one, trichlorfon respectively: O,O-dimethyl-(2, 2, 2-trichloro-1-hydroxy ethyl)-phosphonate (T), from Jiangsu Hongze Chemical and Industry Co., Ltd. The $\mathrm{SiO}_{2}$ precursors were: tetraethylorthosilicate (TEOS) from Merck, colloidal silica Ludox SM-30 type (CS) from Aldrich, and a sodium silicate solution 26 wt.\% $\mathrm{SiO}_{2}$ (SS) from Merck, respectively. In the case of TEOS, the ethanol (from Riedel de Haën) has been used as solvent. The gelation of all prepared sol-gel materials was ac- complished at neutral $\mathrm{pH}$, which is also totally harmless for the soil in case of application. The $\mathrm{pH}$ adjustment was realized with a 25 wt. $\% \mathrm{HNO}_{3}$ solution. The experiments were made at the room temperature. All samples have been prepared under continuous stirring, in a few steps. First, the alkoxide was solved in the corresponding quantity of alcohol (the molar ratio of $\mathrm{SiO}_{2} / \mathrm{ROH}=0.075 /$ 0.515), respectively the colloidal silica and the sodium silicate solutions have been diluted with water, in order to ensure the same $\mathrm{SiO}_{2}$ concentration in all samples (solutions “a”). Then, the aqueous solution of trichlorfon (solution "b") was added drop by drop to solution "a", resulting solution "c". Its $\mathrm{pH}$ was checked and adjusted to the value of 6 . For each of the obtained composite samples the corresponding $\mathrm{SiO}_{2}$ matrices have been prepared, in the same experimental conditions but in the absence of trichlorfon. In order to study the influence of the presence of cyclodextrins over the release of the pesticide from the prepared materials, similar samples to those containing only trichlorfon have been synthesised at the same time, in which $\alpha-, \beta$-, and $\gamma$-cyclodextrin (CD) from Wacker-Chemie GMBH have been included. All cyclodextrin types have been introduced in the reaction mixture as aqueous solutions, simultaneously with the trichlorfon, in the quantity imposed by the solubility limit. The composition of the corresponding samples was: 19 wt.\% T, 24 wt.\% CD and 57 wt.\% $\mathrm{SiO}_{2}$, respectively.

In the present work, a number of 15 gels have been prepared. Their names were established depending on the used $\mathrm{SiO}_{2}$ precursor, as follows: TEOS, CS, and SS (for the silica matrices); TEOS $+\mathrm{T}, \mathrm{CS}+\mathrm{T}$, and $\mathrm{SS}+\mathrm{T}$ (for the silica/trichlorfon composites); TEOS + T + CD ( $\alpha-$, $\beta-$, or $\gamma-), \mathrm{CS}+\mathrm{T}+\mathrm{CD}(\alpha-, \beta-$, or $\gamma-)$ and SS + T + CD $(\alpha-, \beta-$, or $\gamma-$ ), respectively (for those composites in which both trichlorfon and cyclodextrin have been included in the silica matrices).

\subsection{Methods of Characterization}

The structural characterization of the prepared samples was accomplished by IR spectroscopy, using a FT-IR NICOLET $6700\left(400-4000 \mathrm{~cm}^{-1}\right)$ spectrophotometer. Their thermal behaviour was studied up to $800^{\circ} \mathrm{C}$, using a Mettler Toledo Star System TGA/SDTA851/LF $1600^{\circ} \mathrm{C}$, with a heating rate of $10 \mathrm{~K} \mathrm{~min}^{-1}$, dynamic air atmosphere, and a flow rate of $50 \mathrm{~mL} \mathrm{~min}^{-1}$.

The release of trichlorfon from the silica matrix was investigated during a series of batch experiments. In these tests, a quantity of sample corresponding to 100.0 mg trichlorfon (between $0.3863 \mathrm{~g}$ and $0.8803 \mathrm{~g}$ sample) was contacted with $100 \mathrm{~mL}$ ultrapure water and continuously mixed (150 rpm.) in a closed glass vessel at the temperature of $21 \pm 1^{\circ} \mathrm{C}$ using a thermostated shaker (GFL 3033). Trichlorfon concentrations from the aque- 
ous solutions were determined by High Performance Liquid Chromatography (HPLC) technique, using a Varian Pro Star chromatograph equipped with an UV-Vis detector $(\lambda=200 \mathrm{~nm})$. A column Inertsil ODS2 $(25 \mathrm{~cm} \times$ $4.6 \mathrm{~cm} \times 1 / 4$ ") was used as stationary phase. The mobile phase was a mixture of acetonitrile/water $(1: 1, \mathrm{v} / \mathrm{v})$ with

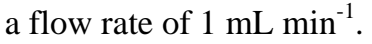

\section{Results and Discussion}

In the experimental conditions mentioned above, 15 gels have been obtained after gelation times of hours (for the samples synthesized from TEOS as silica precursor), days (for the samples obtained from CS), and minutes (for the samples proceeding from SS), respectively. They have been dried at room temperature and subjected to characterization, as follows:

\subsection{IR Spectroscopy}

All the prepared samples, and the organic compounds included in the sol-gel silica matrices (trichlorfon, $\alpha-, \beta$-, and $\gamma$-cyclodextrin) have been structurally characterized using the IR spectroscopy. Figure 1 presents the IR spectra of the sol-gel prepared pesticide-silica composites in the absence of cyclodextrins in comparison with the corresponding spectra of the silica matrices that proceed from three different precursors and with the trichlorfon IR spectrum.

The IR spectra of the prepared samples were compared to the trichlorfon IR spectrum in order to emphasize the fact that, regardless of the $\mathrm{SiO}_{2}$ precursor, the pesticide was embedded inside the sol-gel matrix. Some of its characteristic vibration bands are absent from the spectra of the composite samples. The assignments of the wave number values from Figure 1 which refer to the silica matrices proceeding from different precursors are presented in Table 1.

The characteristic vibration bands for a $\mathrm{SiO}_{2}$ gel could be observed, no matter of the used precursor.

Regarding the IR band frequencies of trichlorfon presented in Figure 1, they correspond to the following vibrations: $\mathrm{OH}$ stretching at $3384 \mathrm{~cm}^{-1}$, $\mathrm{CH}$ stretching between 2800 and $3000 \mathrm{~cm}^{-1}, \mathrm{OH}$ bending at $1638 \mathrm{~cm}^{-1}$, $\mathrm{CH}$ deformation vibrations at 1461 and $1380 \mathrm{~cm}^{-1}$, PO stretching at 1240 and $1203 \mathrm{~cm}^{-1}$, CO stretching at 1085 and $1041 \mathrm{~cm}^{-1}$, and $\mathrm{C}-\mathrm{Cl}$ vibration between 850 and 550 $\mathrm{cm}^{-1}$.

From Figure 1 it can be concluded that the silica matrix, no matter of its provenience, could be an excellent carrier for trichlorfon as embedded organophosphorous pesticide. Subsequent investigations (e.g. release tests) will prove that these matrices are also able to release the incorporated pesticide from their pores.

Figure 2 presents the comparison between the IR spec-
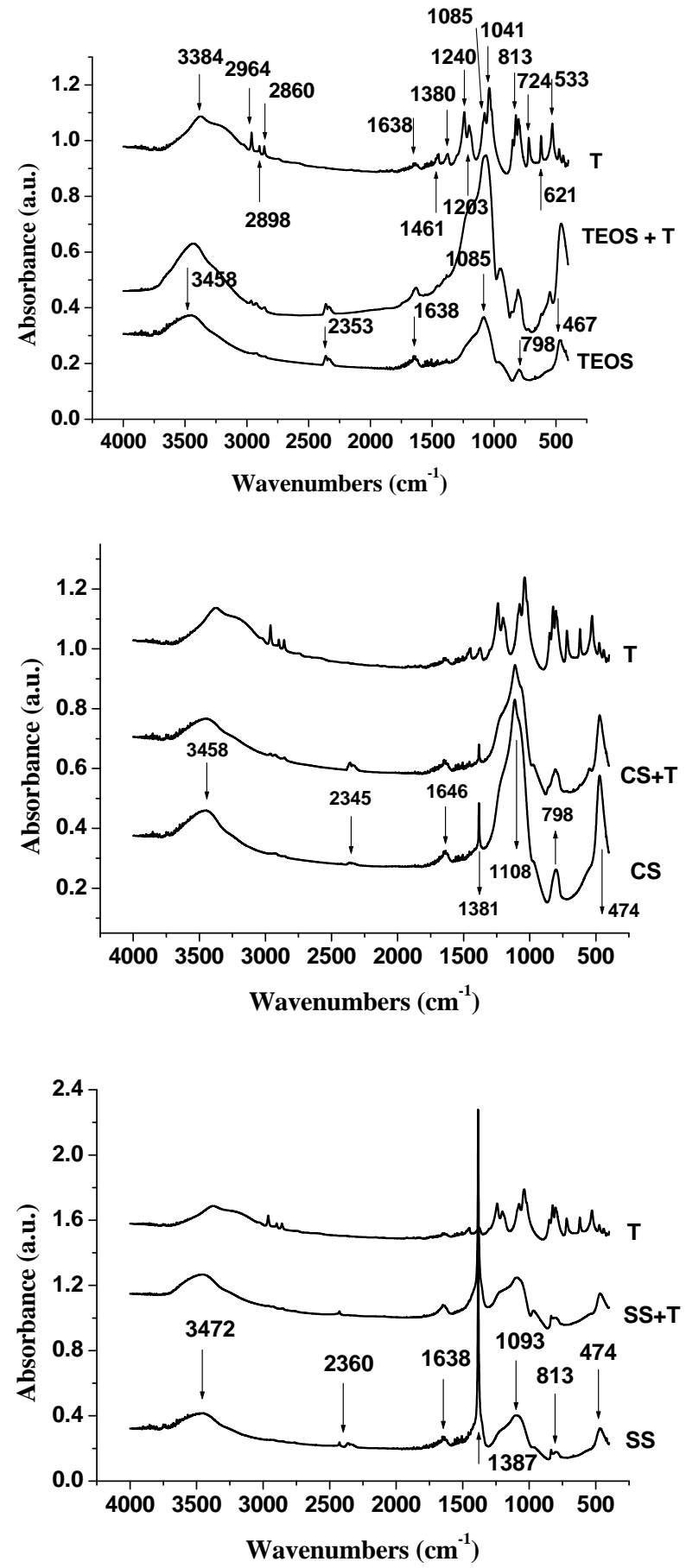

Figure 1. IR spectra of trichlorfon, of the sol-gel pesticidesilica composite samples and of the corresponding silica matrices obtained from different precursors: TEOS, CS, and SS, respectively.

tra of the pesticide-silica composites and those of the corresponding samples in which cyclodextrins have also been included. For the same silica matrix, all the spectra of the samples with cyclodextrins are similar. For this 
Table 1. IR band frequencies and their assignments for the silica gels issued from different precursors (TEOS, CS and SS, respectively).

\begin{tabular}{|c|c|c|}
\hline $\mathrm{SiO}_{2}$ precursor & Wavenumber $\left[\mathrm{cm}^{-1}\right]$ & Assignment \\
\hline TEOS, CS & 3458 & \multirow{2}{*}{ Structural $\mathrm{OH}^{-}$} \\
\hline SS & 3472 & \\
\hline SS & 2360 & \multirow{3}{*}{$\mathrm{CO}_{2}$ vib. } \\
\hline TEOS & 2353 & \\
\hline CS & 2345 & \\
\hline CS & 1646 & \multirow{2}{*}{$\delta \mathrm{HOH}$} \\
\hline TEOS, SS & 1638 & \\
\hline SS & 1387 & \multirow{2}{*}{$\mathrm{NO}_{3}^{-}$vib. } \\
\hline CS & 1381 & \\
\hline CS & 1108 & \multirow{3}{*}{$v_{\text {as }} \mathrm{Si}-\mathrm{O}-\mathrm{Si}$} \\
\hline SS & 1093 & \\
\hline TEOS & 1085 & \\
\hline SS & 813 & \multirow{2}{*}{$v_{\text {sym }} \mathrm{Si}-\mathrm{O}-\mathrm{Si}$} \\
\hline TEOS, CS & 798 & \\
\hline CS, SS & 474 & \multirow{2}{*}{$\delta$ O-Si-O } \\
\hline TEOS & 467 & \\
\hline
\end{tabular}

reason only those containing $\gamma$-CD have been presented. The IR spectrum of the $\gamma$-CD has also been included.

A very good correspondence between our data referring to the IR spectra of cyclodextrins and the literature ones [43-46] has been obtained. The following IR vibration bands have been registered: $\mathrm{OH}$ stretching at 3370 $\mathrm{cm}^{-1}$, CH stretching at $2945 \mathrm{~cm}^{-1}$, the $\mathrm{H}$ bond vibration band at $2366 \mathrm{~cm}^{-1}$, OH bending at $1660 \mathrm{~cm}^{-1}$, CH deformation at 1478 and $1351 \mathrm{~cm}^{-1}$, CO stretching and $\mathrm{OH}$ bending at $1190 \mathrm{~cm}^{-1}, \mathrm{CO} / \mathrm{CC}$ stretching at 1115 and $1015 \mathrm{~cm}^{-1}$, and the pyranose ring vibration at 739 and $584 \mathrm{~cm}^{-1}$.

The literature data [47-49] recognize the limits of the IR spectroscopy method regarding the structural investigation of the inclusion compounds of the cyclodextrins. The explanation is simple: the characteristic bands of the cyclodextrins represent an overwhelming part of the complex. Therefore, they are hardly influenced by the complex formation. Only slight alterations of the spectrum of the host could be observed due to the guest molecules, expressed by shifted bands or altered intensities of the IR signals. However, there are some situations in which the cyclodextrins inclusion complexes formation may be proved by the IR spectroscopy analysis [50]. In the present study the identification of the inclusion compounds eventually formed between trichlorfon and cyclo-
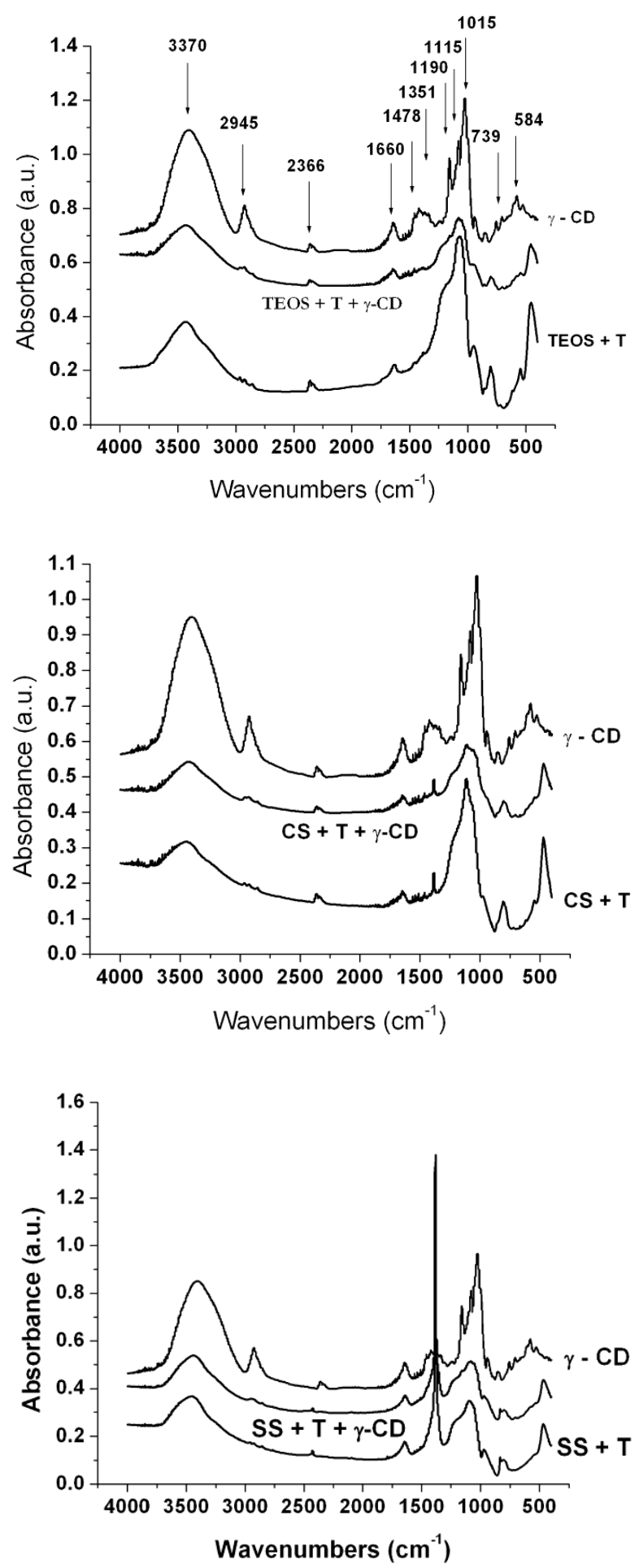

Figure 2. IR spectra of the sol-gel pesticide-silica composites prepared from different $\mathrm{SiO}_{2}$ precursors, of the corresponding samples in which $\gamma$-CD has been added, and of the $\gamma$-CD.

dextrins has become more difficult because of the silica matrix presence. 


\subsection{Thermal Analysis}

The use of the thermoanalytical techniques in order to investigate the formation of the cyclodextrins inclusion compounds is well recognized for three decades [41,42, 50,51].

All the prepared samples and the organic compounds included in the sol-gel silica matrices: trichlorfon, $\alpha-, \beta$-, and $\gamma$-cyclodextrin, respectively, have been characterized by thermal analysis. Table 2 and Figures 3-5 present the obtained results.

In what the three types of cyclodextrins are concerned, the obtained results presented in Table 1 are in agreement with the literature data [41,47,50,52-54].

Because the registered derivatograms of the sol-gel samples obtained with different cyclodextrins $(\alpha-, \beta$-, and $\gamma$-CD, respectively) are similar, Figures 3-5(c) present only the experimental results obtained using $\gamma$-CD.

As seen in Figures 3-5, the nature of the silica matrix has a significant influence over the thermal behavior of the material. The trichlorfon elimination (which starts in the pure compound at $196^{\circ} \mathrm{C}$ ) is modified in the presence of the matrix: in the case of the organic precursor TEOS, it takes place at $409^{\circ} \mathrm{C}$, in the case of the inorganic precursors, the corresponding temperatures are lower: $182^{\circ} \mathrm{C}$ for the colloidal silica and $245^{\circ} \mathrm{C}$, respectively, for the sodium silicate. Regarding the elimination of trichlorfon in the presence of cyclodextrins ( $\alpha-, \beta$-, and $\gamma$-CD), only in the case of the matrix proceeded from TEOS, the process takes place at temperatures $\left(195-202^{\circ} \mathrm{C}\right)$ comparable with those of the pure trichlorfon $\left(196-258^{\circ} \mathrm{C}\right)$. In the case of the inorganic $\mathrm{SiO}_{2}$ precursors (CS and SS, respectively), the trichlorfon elimination starts at modified temperatures $\left(156-164^{\circ} \mathrm{C}\right.$ for $\mathrm{CS}$ and $155-196^{\circ} \mathrm{C}$ for $\mathrm{SS})$. The influence of the silica matrix on the thermal behavior of the sol-gel prepared materials can also be seen in the major modification of the temperatures corresponding to the combustion of cyclodextrins. No matter the type $(\alpha-, \beta-$, or $\gamma-C D)$, they are eliminated by combustion from the samples at much lower temperatures ( $\alpha$-CD: $305-330^{\circ} \mathrm{C}, \beta-\mathrm{CD}$ : $295-311^{\circ} \mathrm{C}$, and $\gamma-\mathrm{CD}$ : $310-335^{\circ} \mathrm{C}$ ), compared to the temperatures of combustion of the pure cyclodextrins which are around $500^{\circ} \mathrm{C}(\alpha-\mathrm{CD}$ : $499^{\circ} \mathrm{C}, \beta-\mathrm{CD}: 480^{\circ} \mathrm{C}$, and $\gamma-\mathrm{CD}: 498^{\circ} \mathrm{C}$ ).

It can be assumed that the shift of the decomposition temperatures is due not only to the silica matrices but also to the inclusion compounds formation. The supposition could be correct for all the sol-gel prepared samples containing both trichlorfon and cyclodextrin, because the melting step corresponding to the trichlorfon could not be observed. In fact, the lack of the melting step of the guest molecule from the derivatograms is considered to be the proof of the inclusion compound formation [41,42,

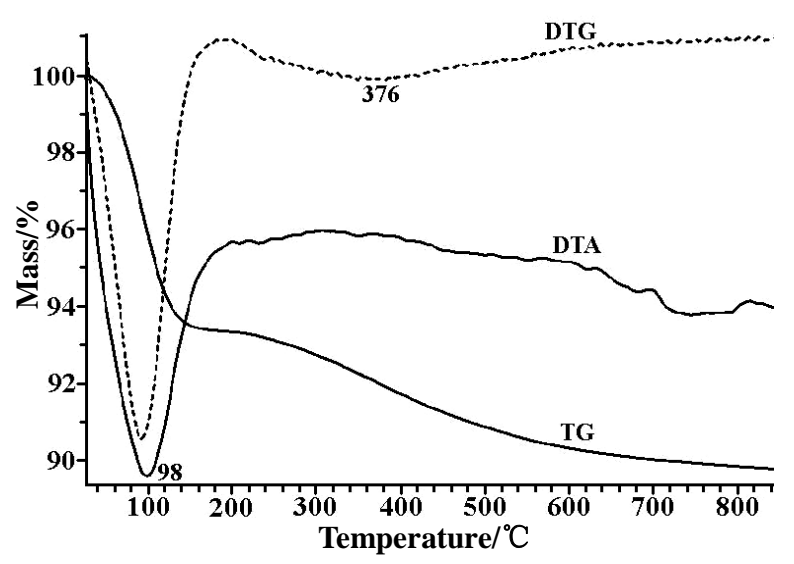

(a)

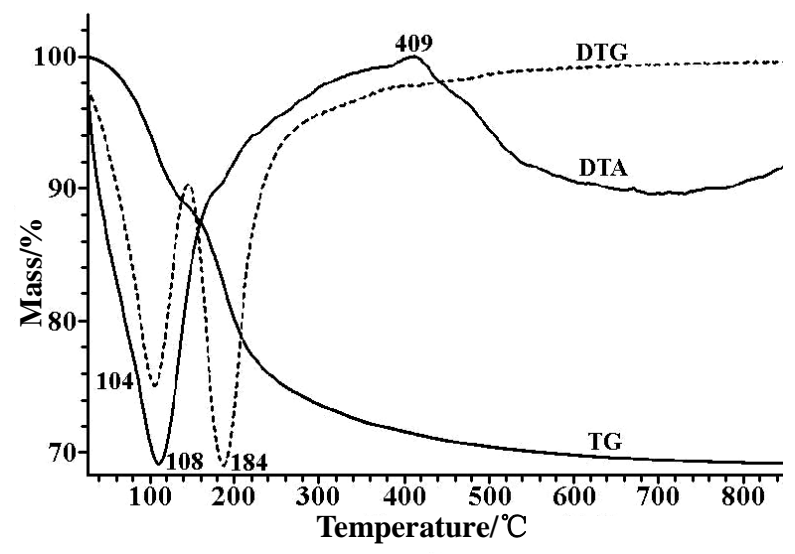

(b)

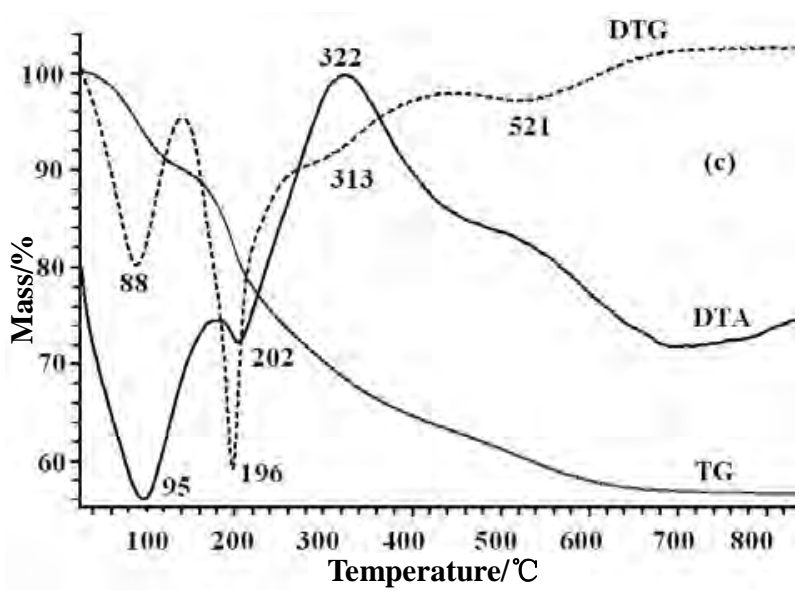

(c)

Figure 3. Thermal behavior of the silica matrix obtained from TEOS (a) and of the sol-gel samples prepared from TEOS in the presence of $T(b)$ and of both $T$ and $\gamma-C D$ (c).

50]. Therefore, it can be concluded that the thermal analysis indicates that the pesticide molecules have in- 


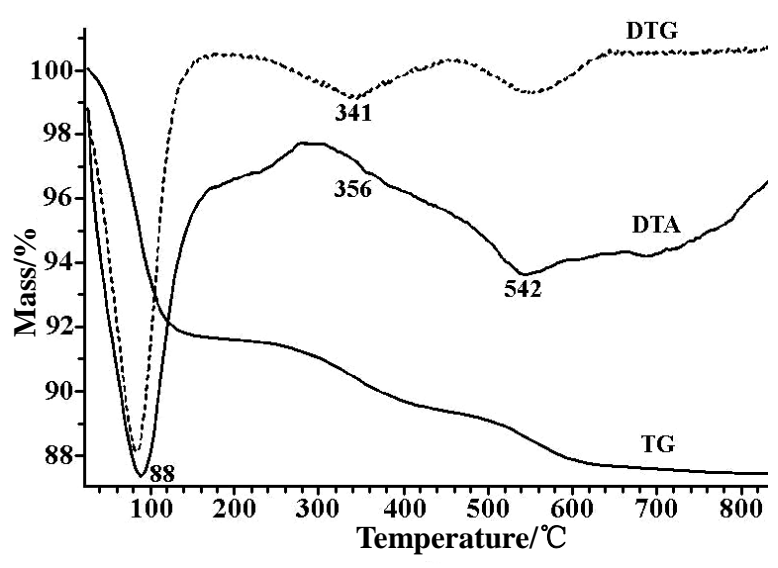

(a)

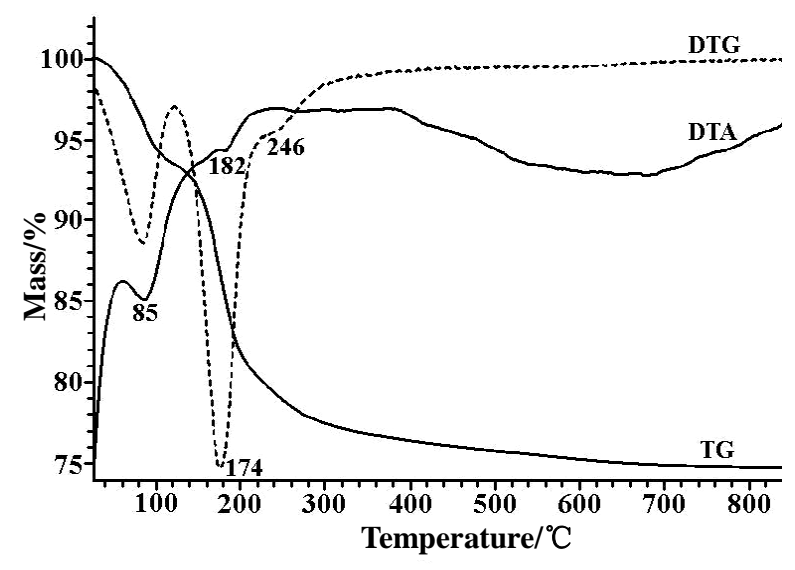

(b)

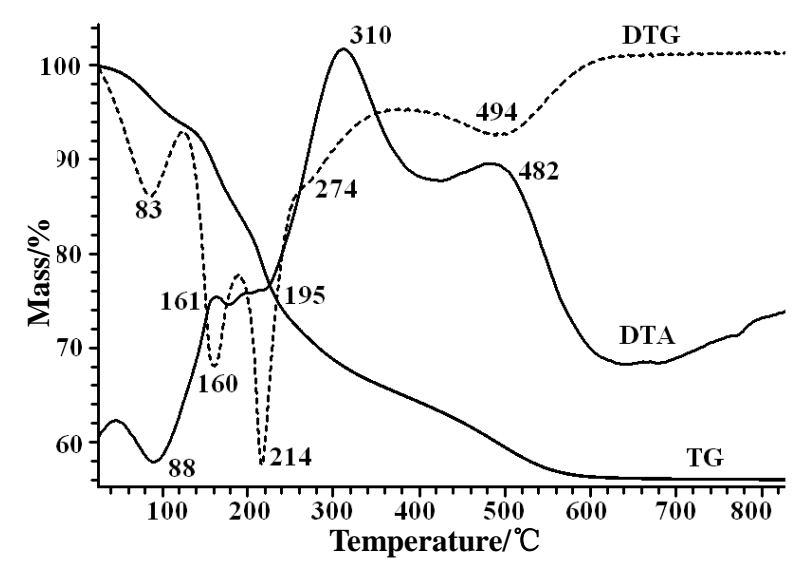

(c)

Figure 4. Thermal behavior of the silica matrix obtained from CS (a) and of the sol-gel samples prepared from CS in the presence of $T$ (b) and of both $T$ and $\gamma$-CD (c).

teracted with the cavity of the cyclodextrins host molecules, forming the inclusion complexes. Some doubts still

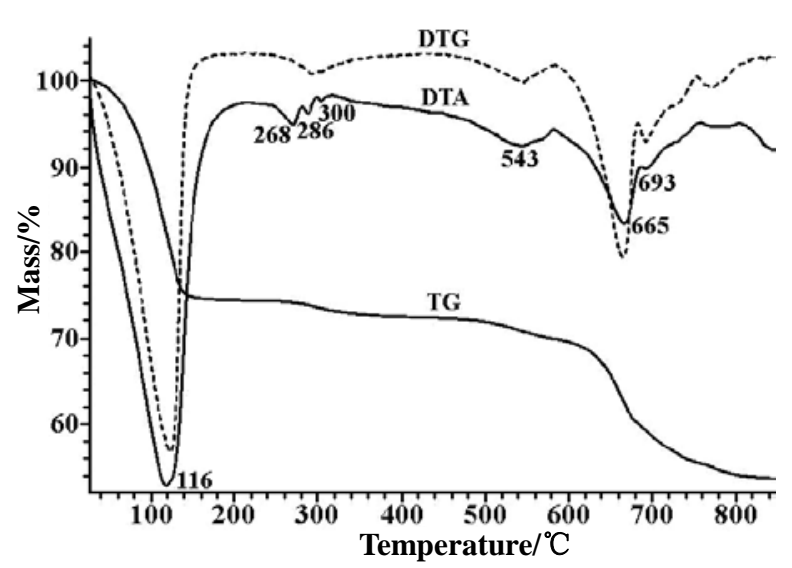

(a)

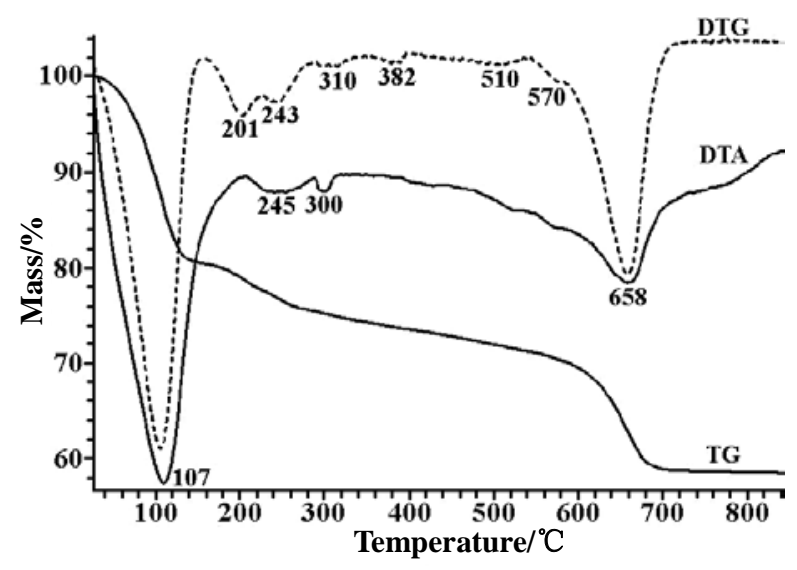

(b)

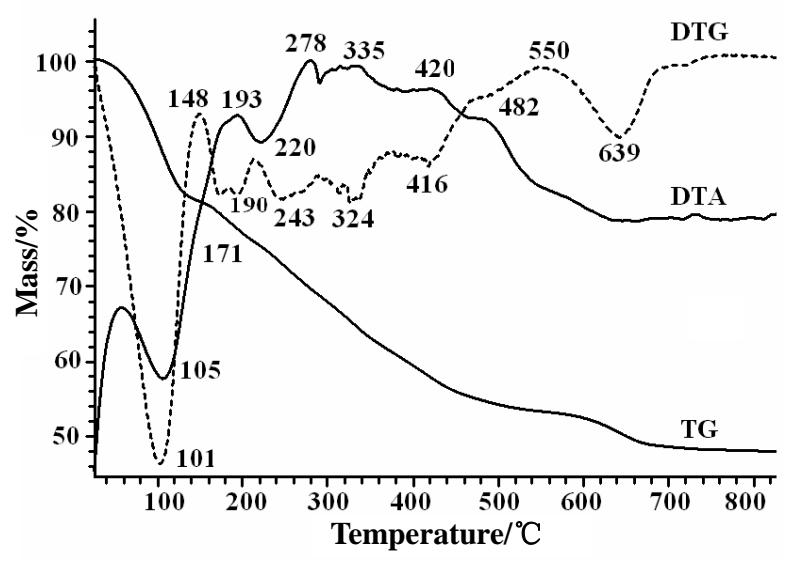

(c)

Figure 5. Thermal behavior of the silica matrix obtained from SS (a) and of the sol-gel samples prepared from SS in the presence of $T(b)$ and of both $T$ and $\gamma$-CD (c).

exist, taking into account the fact that in the samples prepared without cyclodextrins, the silica matrix (no 
Table 2. Thermal behavior of the organic compounds used in the sol-gel materials preparation.

\begin{tabular}{|c|c|c|c|c|c|c|}
\hline \multirow{2}{*}{$\begin{array}{l}\text { Included organic } \\
\text { compound (OC) }\end{array}$} & \multirow{2}{*}{$\begin{array}{c}\text { Range of } \\
\text { temperature } \\
{\left[{ }^{\circ} \mathrm{C}\right]}\end{array}$} & \multirow{2}{*}{$\begin{array}{l}\text { Temperature of the } \\
\text { thermal effect }\left[{ }^{\circ} \mathrm{C}\right]\end{array}$} & \multirow{2}{*}{ Thermal effect } & \multicolumn{2}{|c|}{ Mass loss [\%] } & \multirow{2}{*}{ Assignment } \\
\hline & & & & partial & total & \\
\hline \multirow{4}{*}{$\mathrm{T}$} & $20-120$ & 76 & endothermic & - & & Melting \\
\hline & $120-230$ & 196 & endothermic & 73.49 & 94.16 & Decomposition \\
\hline & $230-280$ & 258 & endothermic & 10.27 & & Decomposition \\
\hline & $280-800$ & & & 10.40 & & Decomposition \\
\hline \multirow{3}{*}{$\alpha-C D$} & $20-140$ & 73,107 & endothermic & 9.94 & & Water elimination \\
\hline & $140-390$ & 274 & endothermic & 68.24 & 99.28 & Decomposition \\
\hline & $390-800$ & 499 & exothermic & 21.10 & & Combustion \\
\hline \multirow{4}{*}{$\beta$-CD } & $20-130$ & 102 & endothermic & 13.33 & & Water elimination \\
\hline & $130-250$ & & endothermic & - & 100.18 & Melting \\
\hline & $250-390$ & 268 & endothermic & 64.46 & & Decomposition \\
\hline & $390-800$ & 480, 532 & exothermic & 22.39 & & Combustion \\
\hline \multirow{3}{*}{$\gamma$-CD } & $20-130$ & 88 & endothermic & 10.33 & & Water elimination \\
\hline & $130-390$ & 287 & endothermic & 70.55 & 101.10 & Decomposition \\
\hline & $390-800$ & 362,498 & exothermic & 20.22 & & Combustion \\
\hline
\end{tabular}

matter its provenience) seems to be a protection medium for the trichlorfon which doesn't melt when it is included.

In order to clarify this aspect and to evidence the presence of the organic compounds (trichlorfon and cyclodextrins) inside the prepared sol-gel silica matrices, even after their heating up to $800^{\circ} \mathrm{C}$, the mass losses corresponding to each of the samples have been calculated from the thermal analysis results. They are presented in Tables 3-5 for each of the silica precursors used for the preparation of the silica matrix, in order to accomplish a comparative study.

As it can be seen, except for the samples obtained from sodium silicate as precursor of the silica matrix, in all cases the values of "included organic compound" (IOC) were higher than those corresponding to the "total mass loss of the sample" (TML). This fact indicates that the $\mathrm{SiO}_{2}$ matrices proceeded from TEOS and colloidal silica respectively, are better hosts for the organic materials, compared to that obtained from sodium silicate.

In order to establish both the role of the silica matrix and of the presence of cyclodextrins on the release properties of the materials, the thermal analysis results need supplementary information to elucidate the formation of the inclusion compounds and the properties of the prepared sol-gel samples. Thus, trichlorfon release tests have been accomplished.

\subsection{Trichlorfon Release Tests}

The release of trichlorfon from the sol-gel silica matrices in the absence and in the presence of cyclodextrins has been assessed by high-performance liquid chromatography (HPLC) measurements.

Relatively recent literature data [7] evidence the fact that although the organophosphorous pesticides $\left(\mathrm{OPP}_{\mathrm{s}}\right)$ are among the most widely employed world-wide, only a limited number of representative compounds has been separated by high-performance liquid chromatography (HPLC). Regarding the gas chromatography (GC), the number of publications is even much smaller. The explanation could consist in the fact that the analyses are still based on an empirical selection of the stationary phase, and they depend practically on the experience obtained on a case by case basis. Poor recoveries of compounds such as trichlorfon and dichlorvos (a possible trichlorfon transformation product) have been reported [55]. Despite these informations, in our work trichlorfon release tests have been accomplished, in order to establish that the sol-gel silica matrices could represent new and relatively cheap pesticide carriers with delivery properties. The trichlorfon concentrations have been determined at intervals of $1,2,3,6,12$ and 24 hours, respectively. The experimental results are presented in Figures 6-8.

Figure 6 refers to the sol-gel samples in which the pesticide was embedded in the silica matrices obtained from TEOS and from colloidal silica (CS) in the absence of cyclodextrins. It can be seen that both silica matrices 
Table 3. The mass loss referring to the included organic compounds of the sol-gel prepared materials, using $\mathrm{TEOS}^{\text {as }} \mathrm{SiO}_{2}$ precursor.

\begin{tabular}{|c|c|c|c|c|c|c|}
\hline \multirow{2}{*}{$\begin{array}{l}\text { Type of included } \\
\text { organic compound }\end{array}$} & \multicolumn{3}{|c|}{ Quantity of included organic compound [mg] } & \multicolumn{2}{|c|}{ Registered mass loss [mg] } & \multirow{2}{*}{$\begin{array}{c}\text { Range of } \\
\text { temperature }\left[{ }^{\circ} \mathrm{C}\right]\end{array}$} \\
\hline & $\mathrm{T}$ & $\mathrm{CD}$ & IOC $^{*}$ & $\mathrm{TML}^{* *}$ & per stage & \\
\hline $\mathrm{T}$ & 13.94 & - & 13.94 & 12.38 & 12.38 & $140-800$ \\
\hline & & & & & 11.16 & $140-280$ \\
\hline \multirow[t]{3}{*}{$\mathrm{T}+\alpha-\mathrm{CD}$} & 9.55 & 12.23 & 21.78 & 20.51 & 4.58 & $280-420$ \\
\hline & & & & & 4.77 & $420-800$ \\
\hline & & & & & 4.63 & $130-280$ \\
\hline \multirow[t]{3}{*}{$\mathrm{T}+\beta-\mathrm{CD}$} & 6.40 & 8.19 & 14.59 & 9.13 & 2.49 & $280-420$ \\
\hline & & & & & 2.01 & $420-800$ \\
\hline & & & & & 8.05 & $140-280$ \\
\hline \multirow[t]{2}{*}{$\mathrm{T}+\gamma-\mathrm{CD}$} & 7.64 & 9.78 & 17.42 & 14.79 & 3.53 & $280-420$ \\
\hline & & & & & 3.21 & $420-800$ \\
\hline
\end{tabular}

*IOC - The "included organic compound" refers only to the trichlorfon and cyclodextrin introduced in the sample by means of the chemical synthesis. It excludes the organic precursor (TEOS) and the alcohol used in the synthesis as solvent. "TML - The "total mass loss of the sample" is composed from: (a) the mass loss of trichlorfon and cyclodextrin, (b) the organic matter eliminated both from solvent and from the organic silica precursor (TEOS), (c) the mass loss of the water proceeded from the moistures of trichlorfon and cyclodextrins, (d) the mass loss of the water proceeded from the inorganic silica precursors (CS and SS), and (e) the nitrate eliminated from the samples proceeded from SS.

Table 4. The mass loss referring to the included organic compounds of the sol-gel prepared materials, using $\mathrm{CS}_{\text {as }} \mathrm{SiO} \mathrm{P}_{2} \mathrm{pre}^{-}$ cursor.

\begin{tabular}{|c|c|c|c|c|c|c|}
\hline \multirow{2}{*}{$\begin{array}{l}\text { Type of included } \\
\text { organic compound }\end{array}$} & \multicolumn{3}{|c|}{ Quantity of included organic compound [mg] } & \multicolumn{2}{|c|}{ Registered mass loss [mg] } & \multirow{2}{*}{ Range of temperature $\left[{ }^{\circ} \mathrm{C}\right]$} \\
\hline & $\mathrm{T}$ & CD & IOC & TML & per stage & \\
\hline \multirow{2}{*}{$\mathrm{T}$} & 10.92 & - & 10.92 & 8.44 & 5.97 & $120-220$ \\
\hline & & & & & 2.47 & $220-800$ \\
\hline \multirow{4}{*}{$\mathrm{T}+\alpha-\mathrm{CD}$} & & & & & 5.28 & $120-190$ \\
\hline & 10.86 & 13.89 & 24.75 & 20.91 & 7.04 & $190-260$ \\
\hline & & & & & 3.62 & $260-370$ \\
\hline & & & & & 4.97 & $370-800$ \\
\hline \multirow{3}{*}{$\mathrm{T}+\beta-\mathrm{CD}$} & & & & & 2.80 & $100-180$ \\
\hline & 6.12 & 7.83 & 13.95 & 11.12 & 5.98 & $180-380$ \\
\hline & & & & & 2.34 & $380-800$ \\
\hline \multirow{4}{*}{$\mathrm{T}+\gamma-\mathrm{CD}$} & & & & & 4.89 & $120-190$ \\
\hline & 9.87 & 12.64 & 22.51 & 19.53 & 6.34 & $190-260$ \\
\hline & & & & & 3.46 & $260-370$ \\
\hline & & & & & 4.84 & $370-800$ \\
\hline
\end{tabular}

obtained from different $\mathrm{SiO}_{2}$ precursors have included the pesticide inside their pores, having the property to release it in time. But the release properties in the case of the sample obtained from TEOS precursor were better than in the case of CS.

The corresponding release profile for the sample ob- tained from sodium silicate as $\mathrm{SiO}_{2}$ precursor is absent because the trichlorfon was not detected in this case. Studying the degradation and the half-lives of some organophosphorous pesticides (including trichlorfon and dichlorvos) in water samples, Molina et al. [55] show that in many cases transformation products form which 
Table 5. The mass loss referring to the included organic compounds of the sol-gel prepared materials, using $\mathrm{SS}$ as $\mathrm{SiO}_{2}$ precursor.

\begin{tabular}{|c|c|c|c|c|c|c|}
\hline \multirow{2}{*}{$\begin{array}{l}\text { Type of included } \\
\text { organic compound }\end{array}$} & \multicolumn{3}{|c|}{ Quantity of included organic compound [mg] } & \multicolumn{2}{|c|}{ Registered mass loss [mg] } & \multirow{2}{*}{ Range of temperature $\left[{ }^{\circ} \mathrm{C}\right]$} \\
\hline & $\mathrm{T}$ & CD & IOC & TML & per stage & \\
\hline \multirow{2}{*}{$\mathrm{T}$} & 4.41 & - & 4.41 & 7.14 & 2.91 & $150-520$ \\
\hline & & & & & 4.23 & $520-800$ \\
\hline \multirow{2}{*}{$T+\alpha-C D$} & 4.31 & 5.51 & 9.82 & 11.91 & 9.73 & $150-540$ \\
\hline & & & & & 2.18 & $540-800$ \\
\hline \multirow{2}{*}{$\mathrm{T}+\beta-\mathrm{CD}$} & 2.70 & 3.46 & 6.16 & 7.59 & 5.90 & $100-370$ \\
\hline & & & & & 1.69 & $370-800$ \\
\hline \multirow{2}{*}{$\mathrm{T}+\gamma-\mathrm{CD}$} & 4.45 & 5.70 & 10.15 & 13.09 & 11.02 & $150-550$ \\
\hline & & & & & 2.07 & $550-800$ \\
\hline
\end{tabular}

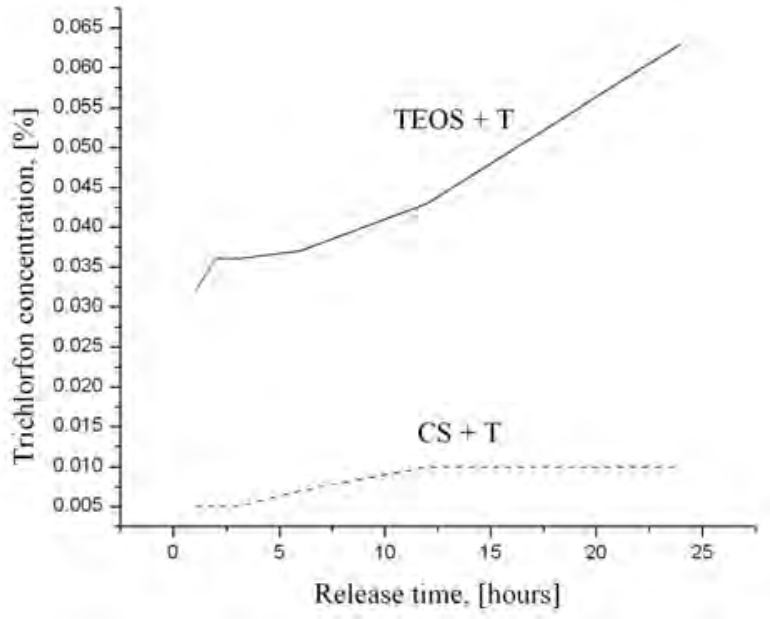

Figure 6. The release profiles of trichlorfon for the sol-gel samples proceeding from TEOS and from $\mathrm{CS}$ as $\mathrm{SiO}_{2}$ precursors.

are more stable than the parent compounds. This could explain the lack of the trichlorfon detection in the case of the sol-gel samples proceeding from the sodium silicate precursor. These samples have involved the greatest water quantity for the synthesis. Moreover, the mentioned samples were the only ones which presented the syneresis phenomenon after their gelation. Shchipunov [34] mentions that the volume shrinkage (syneresis) of the synthesized gel after its preparation is of great importance. He considers that the decrease in volume results in the deterioration of the functional characteristics of the embedded organic molecule. This deterioration is attributable to the poor accessibility of substances owing to the diffusion restriction in small pores and could also explain the experimental chromatographic results obtained for the samples proceeding from sodium silicate.

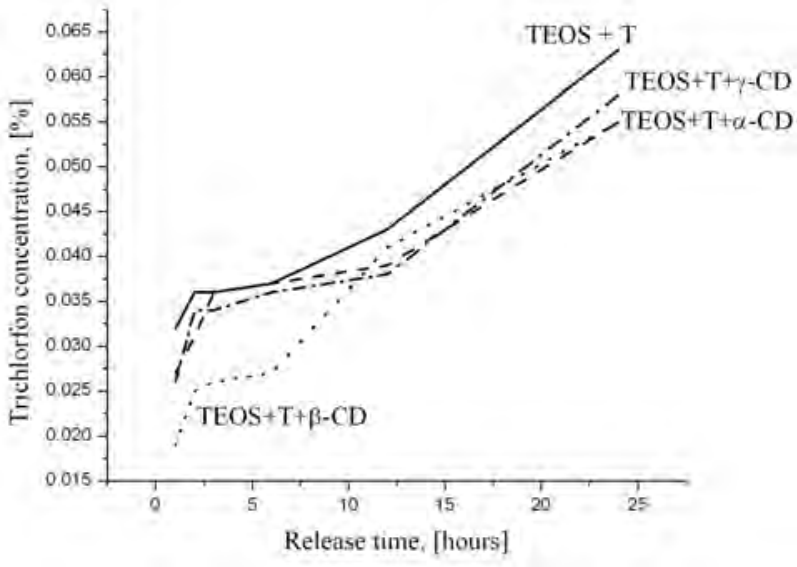

Figure 7. The release profiles of trichlorfon for the sol-gel samples proceeding from TEOS in the absence of cyclodextrins and in the presence of $\alpha-, \beta-$, and $\gamma-C D$, respectively.

The addition of the cyclodextrins in the sol-gel material formulations modifies their release properties, as it can be seen in Figures 7 and $\mathbf{8}$.

Figure 7 shows that the addition of cyclodextrins ( $\alpha$-, $\beta$-, and $\gamma$-CD) in the sol-gel composite formulation proceeding from TEOS as silica precursor hasn't got a benefic effect, because the released trichlorfon concentration decreases in all cases.

Regarding the materials obtained from colloidal silica, the chromatographic results are presented in Figure 8.

Figure 8 shows another way of how cyclodextrin addition influences the release properties of the prepared materials: no matter the type ( $\alpha$-, $\beta$ - or $\gamma$-CD), their presence improves the release of the pesticide, increasing the trichlorfon concentration. The best results have been obtained in the case of $\beta$-CD addition.

From the presented data it can be concluded that the 


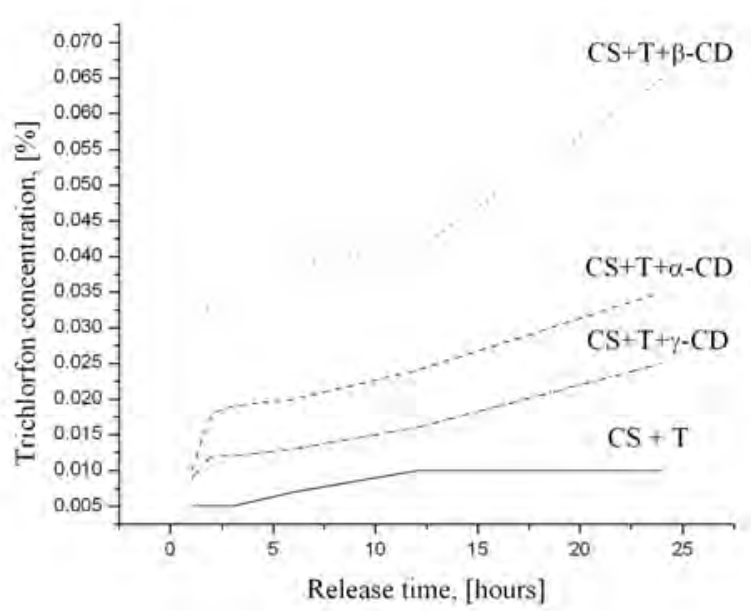

Figure 8. The release profiles of trichlorfon for the sol-gel samples proceeding from $\mathrm{CS}$ in the absence of cyclodextrins and in the presence of $\alpha-, \beta-$, and $\gamma-C D$, respectively.

porous sol-gel silica materials generated from different $\mathrm{SiO}_{2}$ sources (except the sodium silicate) are able to entrap the organophosphorous pesticide (e.g. trichlorfon) in order to create new controlled release carriers. In all cases (except sample CS $+\mathrm{T}$ ) the release of trichlorfon in time is slow and continuous during the studied interval of time (1-24 hours). In the absence of cyclodextrins, better results are obtained in the case of the materials obtained from TEOS, compared to those proceeding from colloiddal silica as $\mathrm{SiO}_{2}$ precursor. The use of cyclodextrins in order to improve the controlled release of the pesticide from the silica matrices showed that only in the case of CS precursor, the addition was successful.

\section{Conclusions}

Two series of sol-gel composite samples have been prepared, using proper recipes. The first consists in trichlorfon as pesticide, embedded in silica gels generated from different silica sources (TEOS, CS, and SS). The second series is likewise synthesized with the first one. The only difference between them is the presence of cyclodextrins in the reaction mixtures.

The release properties of the prepared materials depend both on the nature of the silica matrix and on the presence or absence of cyclodextrin in the reaction mixture. Thus, best results have been obtained for the samples proceeding from TEOS in the absence of cyclodextrins and for those obtained from CS, in the presence of cyclodextrins.

The delivery properties of the sol-gel silica matrices being confirmed, it can be concluded that they can be considered as a new, ecological type of pesticides carriers.

\section{REFERENCES}

[1] S. Paliwal, M. Wales, T. Good, J. Grimsley, J. Wild and A. Simonian, "Fluorescence-Based Sensing of P-Nitrophenol and P-Nitrophenyl Substituent Organophosphates," Analytica Chimica Acta, Vol. 596, No. 1, 2007, pp. 9-15.

[2] M. G. Dantas Silva, A. Aquino, H. S. Dórea and S. Navickiene, "Simultaneous Determination of Eight Pesticide Residues in Coconut Using MSPD and GC/MS," Talanta, Vol. 76, No. 3, 2008, pp. 680-684.

[3] B. Kuswandi, C. I. Fikriyah and A. A. Gani, “An Optical Fiber Biosensor for Chlorpyrifos Using a Single Sol-Gel Film Containing Acetylcholinesterase and Bromothymol Blue,” Talanta, Vol. 74, No. 4, 2008, pp. 613-618.

[4] M. Waibel, H. Schulze, N. Huber and T. T. Bachmann, "Screen-Printed Bienzymatic Sensor Based on Sol-Gel Immobilized Nippostrongylus Brasiliensis Acetylcolinesterase and a Cytochrome P450 BM-3 (CYP102-A1) Mutant," Biosensors and Bioelectronics, Vol. 21, 2006, pp. 1132-1140.

[5] K. S. Yao, D. Y. Wang, C. Y. Chang, et al., "Photocatalytic Disinfection of Phytopathogenic Bacteria by DyeSensitized $\mathrm{TiO}_{2}$ Thin Film Activated by Visible Light," Surface \& Coatings Technology, Vol. 202, No. 4-7, 2007, pp. 1329-1332.

[6] A. N. Ivanov, G. A. Evtugyn, R. E. Gyurcsányi, K. Tóth and H. C. Budnikov, "Comparative Investigation of Electro-Chemical Cholinesterase Biosensors for Pesticide Determination,” Analytica Chimica Acta, Vol. 404, No. 1, 2000, pp. 55-65.

[7] N. Fidalgo-Used, E. Blanco-González and A. Sanz-Medel, "Evaluation of Two Commercial Capillary Columns for the Enantioselective Gas Chromatographic Separation of Organophosphorous Pesticides," Talanta, Vol. 70, No. 5, 2006, pp. 1057-1063.

[8] F. Sopeña, C. Maqueda and E. Morillo, "Controlled Release Formulations of Herbicides Based on MicroEncapsulation,” Ciencia e Investigación Agrarian, Vol. 35, No. 1, 2009, pp. 27-42.

[9] A. T. Doherty, S. Ellard, E. M. Parry and J. M. Parry, “A Study of the Aneugenic Activity of Trichlorfon Detected by Centromere-Specific Probes in Human Lymphoblastoid Cell Lines,” Mutation Research, Vol. 372, No. 2, 1996, pp. 221-231.

[10] X. Hong, J. Qu, J. Chen, et al., “Effects of Trichlorfon on Progesterone Production in Cultured Human GranulosaLutein Cells,” Toxicology in vitro, Vol. 21, No. 5, 2007, pp. 912-918.

[11] X. Hong, J. Qu, Y. Wang, et al., "Study on the Mechanism of Trichlorfon-Induced Inhibition of Progesterone Synthesis in Mouse Leydig Tumor Cells (MLTC-1)," Toxicology, Vol. 234, No. 1-2, 2007, pp. 51-58.

[12] S. Cukurcam, F. Sun, I. Betzendahl, I. D. Adler and U. Eichenlaub-Ritter, "Trichlorfon Predisposes to Aneuploidy and Interferes with Spindle Formation in in vitro Maturing Mouse Oocytes,” Mutation Research, Vol. 564, No. 2, 2004, pp. 165-178. 
[13] R. Ranaldi, G. Gambuti, U. Eichenlaub-Ritter and F. Pacchierotti, "Trichlorfon Effects on Mouse Oocytes Following in vivo Exposure," Mutation Research, Vol. 651, No. 1-2, 2008, pp. 125-130.

[14] B. K. Catalgol, S. Ozden and B. Alpertunga, "Effects of Trichlorfon on Malondialdehyde and Antioxidant System in Human Erythrocytes,” Toxicology in vitro, Vol. 21, No. 8, 2007, pp. 1538-1544.

[15] A. Mehl, T. M. Schanke, A. Torvik and F. Fonnum, "The Effect of Trichlorfon and Methylazoxymethanol on the Development of Guinea Pig Cerebellum,” Toxicology and Applied Pharmacology, Vol. 219, No. 2-3, 2007, pp. 128135.

[16] N. M. Brito, S. Navickiene, L. Polese, E. F. G. Jardim, R. B. Abakerli and M. L. Ribeiro, "Determination of Pesticide Residues in Coconut Water by Liquid-Liquid Extraction and Gas Chromatography with Electron-Capture Plus Thermionic Specific Detection and Solid-Phase Extraction and High-Performance Liquid Chromatography with Ultraviolet Detection," Journal of Chromatography A, Vol. 957, No. 2, 2002, pp. 201-209.

[17] A. G. S. Prado and C. Airoldi, "The Toxic Effect on Soil Microbial Activity Caused by the Free or Immobilized Pesticide Diuron,” Thermochimica Acta, Vol. 394, No. 1-2, 2002, pp. 155-162.

[18] C. Blasco, G. Font and Y. Picó, “Comparison of MicroExtraction Procedures to Determine Pesticides in Oranges by Liquid Chromatography-Mass Spectrometry," Journal of Chromatography A, Vol. 970, No. 1-2, 2002, pp. 201212.

[19] D. K. Rodham, "Colloid and Interface Science in Formulation Research for Crop Protection Products," Current Opinion in Colloid and Interface Science, Vol. 5, No. 5-6, 2000, pp. 280-287.

[20] H. Böttcher, C. Jagota, J. Trepte, K. H. Kallies and H. Haufe, "Sol-Gel Composite Films with Controlled Release of Biocides," Journal of Controlled Release, Vol. 60, No. 1, 1999, pp. 57-65.

[21] M. Hussain, “Atoms in Agriculture: Nuclear Techniques in 'Controlled Release' Pesticide Research,” IAEA Bulletin, Vol. 31, No. 2, 1989, pp. 36-40.

[22] A. Khazaei, D. Soudbar, M. Sadri and H. Hosseini, "Synthesis and Characterization of Poly(biphenyl-2-yl p-styrenesulphonate) as Profungicide in Controlled Release Technique," Journal of the Chinese Chemical Society, Vol. 54, No. 3, 2007, pp. 763-766.

[23] M. Y. Arica, M. Yiğitoğlu, M. Lale, F. N. Kök and V. Hasirci, "Controlled Release of Aldicarb from Carboxymethylcellulase Microcapsules,” Turkish Journal of Chemistry, Vol. 21, No. 2, 1997, pp. 100-104.

[24] K. Y. Choi, K. S. Min, I. H. Park, K. S. Kim and T. Chang, "Microcapsulation of Pesticides by Interfacial Polymerization 1. Polyurethane Microcapsules Containing Oilsoluble Drug,” Polymer (Korea), Vol. 14, No. 4, 1990, pp. 392-400.

[25] M. Y. El-Shoura, S. T. Badr, S. A. El-Khishen and M. M. Abu Elamayem, "Effect of Controlled Release Formula- tions of Carbofuran Soil Fertilizers and their Mixtures on Root-Knot Nematode on Tomato Plants,” Journal of King Saud University. Agricultural Sciences, Vol. 4, No. 1, 1992, pp. 69-77.

[26] H. Schmidt, "Chemistry of Material Preparation by the Sol-Gel Process,” Journal of Non-Crystalline Solids, Vol. 100, No. 1-3, 1988, pp. 51-64.

[27] J. D. Mackenzie, "Hybrid Organic-Inorganic Materials," In: J. E. Mark, C. Y.-C. Lee and P. A. Bianconi, Eds., Hybrid Organic-Inorganic Composites, ACS Symposium Series 585, Washington, D.C., 1998, pp. 226-236.

[28] J. Livage, F. Beteille, C. Roux, M. Chatry and P. Davidson, "Sol-Gel Synthesis of Oxide Materials," Acta Materialia, Vol. 46, No. 3, 1998, pp. 743-750.

[29] J. D. Wright and N. A. J. M. Sommerdijk, "The Chemistry of Sol-Gel Silicates,” In: D. Phillips, P. O’Brien and S. Roberts, Eds., Advanced Chemistry Texts, OPA N.V., Gordon and Breach Science Publishers, New York, 2001, pp. 33-52.

[30] Y. A. Shchipunov and T. Y. Karpenko, "Hybrid Polysaccharide-Silica Nanocomposites Prepared by the Sol-Gel Technique,” Langmuir, Vol. 20, No. 10, 2004, pp. 3882 3887.

[31] Y. A. Shchipunov, T. Y. Karpenko, I. Y. Bakunina, Y. V. Burtseva and T. N. Zvyagintseva, "A New Precursor for the Immobilization of Enzymes inside Sol-Gel Derived Hybrid Silica Nanocomposites Containing Polysaccharides," Journal of Biochemical and Biophysical Methods, Vol. 58, No. 1, 2004, pp. 25-38.

[32] Y. A. Shchipunov, T. Y. Karpenko and A. V. Krekoten, "Hybrid Organic-Inorganic Nanocomposites Fabricated with a Novel Biocompatible Precursor Using Sol-Gel Processing," Composite Interfaces, Vol. 11, No. 8-9, 2005, pp. 587-607.

[33] Y. A. Shchipunov, A. V. Krekoten, V. G. Kuryavyi and I. N. Topchieva, "Microporous Nanocomposite Material Synthesized by Sol-Gel Processing in the Presence of Cyclodextrins," Colloid Journal, Vol. 67, No. 3, 2005, pp. 380-384.

[34] Y. A. Schipunov, "Entrapment of Biopolymers into Sol-Gel Derived Silica Nanocomposites,” In: E. RuizHitzky, K. Ariga and Y. M. Lvov, Eds., Bio-Inorganic Hybrid Nanomaterials, Copyright WILEY-VCH Verlag GmbH \& Co. KGaA, Weinheim, 2008, pp. 75-112.

[35] M. Răileanu, “The Use of Sol-Gel Method for Biomaterials Preparation,” Revue Roumaine de Chimie, Vol. 51, No. 10, 2006, pp. 941-962.

[36] C. Van Hooidonk and J. C. A. E. Breebaart-Hansen, "Model Studies for Enzyme Inhibition. Part IV. The Association of Some Alkyl Methylphosphonates with $\alpha$ cyclodextrin in an Aqueous Medium,” Recueil, Vol. 91, 1972, pp. 958-964.

[37] E. M. Del Valle, "Cyclodextrins and their Uses: A Review,” Process Biochemistry, Vol. 39, No. 9, 2004, pp. 1033-1046.

[38] G. Petrović, B. S. Radovanović and O. Jovanović, “Characterization of Pesticide- $\beta$-cyclodextrin Inclusion Com- 
plexes in Aqueous Solution," Physics, Chemistry and Technology, Vol. 3, No. 2, 2005, pp. 151-155.

[39] A. R. Hedges, "Industrial Applications of Cyclodextrins," Chemical Reviews, Vol. 98, No. 5, 1998, pp. 2035-2044.

[40] J. Szejtli, "Past, Present, and Future of Cyclodextrin Research,” Pure and Applied Chemistry, Vol. 76, No. 10, 2004, pp. 1825-1845.

[41] J. Orgoványi, L. Pöppl, K. H. Otta and G. A. Lovas, "Thermoanalytical Method for Studying the Guest Content in Cyclodextrin Inclusion Complexes," Journal of Thermal Analysis and Calorimetry, Vol. 81, No. 2, 2005, pp. 261-266.

[42] Cs. Novák, Z. Éhen, M. Fodor, L. Jicsinszky and J. Orgoványi, "Application of Combined Thermoanalytical Techniques in the Investigation of Cyclodextrin Inclusion Complexes," Journal of Thermal Analysis and Calorimetry, Vol. 84, No. 3, 2006, pp. 693-701.

[43] G. Ioniță, R. Socoteanu and F. Savonea, “ATR/FTIR Study on Silica Prepared Using $\beta$-Cyclodextrine and Urea as Template,” Revue Roumaine de Chimie, Vol. 50, No. 1, 2005, pp. 71-77.

[44] J. M. Gavira, A. Hernanz and I. Bratu, "Dehydration of $\beta$-cyclodextrin. An IR v(OH) Band Profile Analysis," Vibrational Spectroscopy, Vol. 32, No. 2, 2003, pp. 137146.

[45] I. Bratu, S. Astilean, C. Ionesc, E. Indrea, J. P. Huvenne and P. Legrand, "FT-IR and X-ray Spectroscopic Investigations of Na-diclofenac-cyclodextrins Interactions," Spectrochim Acta A, Vol. 54, No. 1, 1998, pp. 191-196.

[46] A. Farcaş, "Semiconducting Polymers with Rotaxane Architecture,” In: Scientific Anales of the Al.I. Cuza University, Volume XLV.XI.VI, Physics of the Condensed State, 1999-2000, pp. 217-223.

[47] J. Szejtli, "Types, Formation and Structures of Inclusion Complexes,” In: J. Szejtli, Cyclodextrins and their Inclusion Complexes, Akadémiai Kiadó, Budapest, 1982, pp. 94-143.

[48] A. Bertoluzza, M. Rossi, P. Taddei, E. Redenti, M. Zanol and P. Ventura, "FT-Raman and FT-IR Studies of 1:2.5 Piroxicam: $\beta$-cyclodextrin Inclusion Compound,” Journal of Molecular Structure, Vol. 480-481, 1999, pp. 535-539.

[49] E. Bilensoy, M. A. Rouf, I. Vural, M. Sen and A. A. Hincal, "Mucoadhesive, Thermosensitive, ProlongedRelease Vaginal Gel for Clotrimazole: $\beta$-cyclodextrin Complex,” AAPS PharmSciTech, Vol. 7, No. 2, 2006, pp. E54-E60.

[50] F. Taneri, T. Güneri, Z. Aigner, O. Berkesi and M. Kata, "Thermoanalytical Studies on Complexes of Clotrimazole with Cyclodextrins," Journal of Thermal Analysis and Calorimetry, Vol. 76, No. 2, 2004, pp. 471-479.

[51] L. P. Fernandes, Zs. Éhen, T. F. Moura, Cs. Novák and J. Sztatisz, "Characterization of Lippia sidoides Oil Extract- $\beta$-cyclodextrin Complexes Using Combined Thermoanalytical Techniques," Journal of Thermal Analysis and Calorimetry, Vol. 78, No. 2, 2004, pp. 557-573.

[52] J.-H. Li, N. Zhang, X.-T. Li, J.-Y. Wang and S.-J. Tian, "Kinetic Studies on the Thermal Dissociation of the Inclusion Complex of $\beta$-cyclodextrin with Cinnamic Aldehide," Journal of Thermal Analysis and Calorimetry, Vol. 49, No. 3, 1997, pp. 1527-1533.

[53] G. Bettinetti, Cs. Novák and M. Sorrenti, “Thermal and Structural Characterization of Commercial $\alpha-, \beta-$, and $\gamma$-cyclodextrins," Journal of Thermal Analysis and Calorimetry, Vol. 68, No. 2, 2002, pp. 517-529.

[54] J. M. Ginés, M. J. Arias, C. Novák, P. J. Sánchez-Soto, A. Ruiz-Conde and E. Morillo, "Thermal Study of Complex Formation of Triamterene with $\beta$-cyclodextrin by SprayDrying and Co-Grinding,” Journal of Thermal Analysis and Calorimetry, Vol. 45, No. 4, 1995, pp. 659-666.

[55] C. Molina, P. Grasso, E. Benfenati and D. Barceló, “Automated Sample Preparation with Extraction Columns Followed by Liquid Chromatography-Ionspray Mass Spectrometry. Interferences, Determination and Degradation of Polar Organophosphorous Pesticides in Water Samples,” Journal of Chromatography A, Vol. 737, No. 1, 1996, pp. 47-58. 